


\title{
MECHANICAL AND FRACTURE ANALYSIS OF WELDED PEARLITIC RAIL STEELS
}

\author{
Aldinton Allie, Heshmat A. Aglan and Mahmood Fateh
}

\begin{abstract}
Welding rail steels using gas metal arc welding shows promise for repairing railhead defects. Finite element analysis was performed on the rail before and during the welding process. It was revealed that the sizes of the heat affected zone (HAZ) and fusion zone would be approximately $15 \mathrm{~mm}$ and $5 \mathrm{~mm}$ respectively. Hardness tests showed that the parent material is harder than both the HAZ and the welded region. The parent steel has ultimate strength, yield strength, and elongation to failure of $1114 \mathrm{MPa}$, $624 \mathrm{MPa}$, and $11.1 \%$ respectively. These values are higher than those of the welded rail steel. The average $K_{I}$ for the parent specimen was $70 \mathrm{MPa} \cdot \mathrm{m}^{0.5}$, while for the welded steel it was $54 \mathrm{MPa} \cdot \mathrm{m}^{0.5}$. The pearlitic steel displayed ductile fracture features immediately ahead of the crack tip but approaching the end of the fracture surface the failure mechanism became less ductile. The welded rail steel in contrast consists of ductile features throughout the entire fracture surface.
\end{abstract}

\section{Introduction}

Welding produces very high temperatures in the area of the weld and these temperatures decrease rapidly as the distance from the weld increases. This heating followed by cooling to ambient temperature produces stresses in the rail. When the temperature of the rail returns to ambient temperature these stresses remain and are referred to as residual stresses [Little and Kamtekar 1998]. To reduce the formation of residual stresses, the rail steel is usually heated before the welding process begins [Funderburk 1997]. This method of heating the rail is called preheating and creates a softer and tougher structure. Properly monitoring and sometimes adjusting the temperature of both the base metal and weld metal before, during, and after welding is more likely to yield a successful weld. Improper rates of heating and cooling may cause defects to be formed in the welded area or the base material [Funderburk 2000]. Examinations and audits of welding procedures on failed welds conducted by Mutton and Alvarez [2004] have shown that the most likely cause of defects is an insufficient preheat temperature. Preheating may be done by gas torches, ovens, or electrical devices depending on the size of the part being welded and the type of welding equipment being used [Funderburk 2000; WTIA 2006]. When preheating, the temperature of the base material must also be in the range of the preheat temperature within $75 \mathrm{~mm}$ of the welded area in all directions [Mutton and Alvarez 2004; Chandler 2008]. The temperature of the welded joint can be checked by using a thermocouple, a temperature indicating crayon, or a contact thermometer [Reis and Harness 2004]. Preheating is done for several reasons; it slows the cooling rate in the base material and weld metal, which produces a more ductile metallurgic structure. This slow cooling also

Keywords: welded rail steels, heat affected zone, welding efficiency, fracture toughness.

This work was sponsored by the Federal Railroad Administration. The authors would also like to acknowledge Mike Cannon, lab manager at Tuskegee University, for his assistance in the welding procedures. 
allows hydrogen to diffuse from the weld metal, reducing the potential for forming imperfections. It also reduces shrinkage stresses that help in reducing imperfections that may be formed in the weld metal or base material [WTIA 2006; Chandler 2008].

The interpass temperature is defined as the temperature of the base metal between the first and last welding pass at the time welding is to be performed [Funderburk 1999; 2000; Mutton and Alvarez 2004; Lincoln 2005]. The interpass temperature is usually considered as more important than the preheat temperature with regards to the mechanical and microstructural properties of the weldment [Lincoln 2005]. A high interpass temperature will reduce the weld metal strength but usually improves toughness due to a finer grain structure with grain size measured in microns. However, if the interpass temperature is excessive the toughness trend is reversed. Therefore, it is important to maintain the minimum interpass temperature to prevent weld defects while at the same time the maximum interpass temperature must be controlled to provide satisfactory mechanical properties [Lincoln 2005]. The proper preheat and interpass temperatures to be used are dependent on the chemical composition and the thickness of the base material [Funderburk 1999; Tojo 2003]. For low carbon steels with a carbon content of approximately $0.3 \%$ a preheat temperature of $25-150^{\circ} \mathrm{C}$ is required. For medium carbon steels with carbon content of approximately $0.3 \%-0.45 \%$ a preheat temperature of $150-260^{\circ} \mathrm{C}$ is required. And for high carbon steels with carbon content exceeding $0.45 \%$ a preheat temperature of $260-425^{\circ} \mathrm{C}$ is required. To determine appropriate temperatures within the ranges of the different carbon content steels, use higher temperatures for higher carbon contents and for larger base materials [Funderburk 1999].

The hardness of a metal is mainly dependent on the phases that are present, with increases in martensite giving an increased hardness [El-Banna et al. 2000]. When conducting hardness testing the distributions of hardness in the weld, heat affected zone (HAZ), and rail base metal should be shown [Saarna and Laansoo 2004]. A weld containing a wide HAZ or having a low hardness in the fusion zone is predisposed to batter, which may contribute to premature failure in the weld [Mutton and Alvarez 2004]. An increase in the cooling rate of a work piece will provide higher hardness values [El-Banna et al. 2000]. However, if the cooling rate is too fast it may cause the base material to crack. Hardness testing is the simplest method for approximating the quality of a rail weld, but on its own it does not give a true assessment of the rail weld. It is therefore complemented by other test results, including tensile, fatigue, and fracture tests, et cetera [Saarna and Laansoo 2004].

Tensile tests are used to determine the weld metal quality in comparison to the parent rail. The ratio of the weld-to-parent ultimate tensile strength is known as the weld efficiency [Orange 1966]. The tensile strength of pearlitic steels has been proven to be dependent on the ferrite-cementite lamellae spacing, with a smaller spacing giving a higher strength [Aglan and Fateh 2006; 2007]. The thermal cycle associated with welding may cause the mechanical properties in the HAZ to be degraded by grain coarsening, precipitation, and by segregation of trace impurities [Kim et al. 2001]. When a sequence of several weld deposits, called a multirun, is used in welding the microstructure of the weld becomes much more complicated as the deposition of each successive layer of weld heat treats the underlying microstructure. This heat treating may apply a temperature high enough to cause the reformation of austenite, which during cooling transforms the part to a different microstructure [Sugden and Bhadeshia 1989; Bhadeshia 1997].

The purpose of fracture toughness testing is to give a measure of the resistance of the material to fracture [Crear 2001, Chapter 5, p. 5-4]. Once the critical crack length is detected in a rail, it is considered 
unsafe and must therefore be removed from the track. There are four methods that may be used to calculate the fracture toughness, including the Charpy v-notch test, the crack tip opening displacement, the plain strain fracture toughness test $\left(K_{I c}\right)$, and the plain stress fracture toughness $\left(K_{I}\right)$. The latter will be used to study the fracture resistance of the welded pearlitic rail steel. Due to the complexity of the welding process, the toughness of welds is dependent on a lot more variables than the toughness of the steel [Bhadeshia 1997]. The toughness of carbon steels has been shown to be dependent on the prior austenite grain size, with a decrease in the grain size increasing the fracture toughness [Gray et al. 1982; Lewandowski and Thompson 1986]. In most cases, an increase in the strength of a steel decreases its toughness. This occurs because as the strength increases, plastic deformation, which is the major energy absorption mechanism during fracture, becomes more difficult [Bhadeshia 1997]. The type of welding process that is used will also play a significant role in the toughness of the steel, because each welding process is different, and forms different microstructures in the process [Bhadeshia 1997]. The general expression that is used to calculate the value of $K_{I c}$ is shown in the following equation:

$$
K_{I c}=\sigma \sqrt{\pi a} f\left(\frac{a}{W}\right),
$$

where $\sigma$ is the residual strength for a notched specimen, $a$ is the crack length, and $f(a / W)$ is a geometrical correctional factor, which is given by the following equation [Aglan and Fateh 2007]:

$$
f\left(\frac{a}{W}\right)=1.12-0.231 \frac{a}{W}+10.55\left(\frac{a}{W}\right)^{2}-21.72\left(\frac{a}{W}\right)^{3}+30.39\left(\frac{a}{W}\right)^{4} .
$$

The ASTM E399, plain strain fracture toughness is generally used in determining $K_{I C}$. This standard requires that the thickness, $t$, and crack length, $a$, both exceed $2.5 \times\left(K_{1 c} / \sigma_{y s}\right)^{2}$ for the result to qualify as a plain strain fracture toughness, $K_{1 c} . K_{1 c}$ is the calculated fracture toughness and $\sigma_{y s}$ is the yield strength of the unnotched sample. For thin specimens, plain stress may be dominant and $K_{I}$ can be designated as the plain stress fracture toughness.

\section{Materials and experimental parameters}

The materials used in the present work were pearlitic rail steels provided by the Transportation Technology Center, Inc. The composition of the material is shown in Table 1. The rail sections provided were approximately $304.8 \mathrm{~mm}$ long. Two grooves were milled in the railhead, each having $25.4 \mathrm{~mm}$ width and $19.05 \mathrm{~mm}$ depth. Each groove was located $63.5 \mathrm{~mm}$ away from an end. This was done to

\begin{tabular}{|lccccc|}
\hline & $\mathrm{C}$ & $\mathrm{Mn}$ & $\mathrm{P}$ & $\mathrm{Si}$ & $\mathrm{Ti}$ \\
Parent & $0.92-1.01$ & $0.69-1.04$ & $\sim 0.015$ & $0.37-0.44$ & $0.001-0.018$ \\
LA-100 & $0.05-0.06$ & $1.55-1.70$ & $0.005-0.007$ & $0.40-0.50$ & $0.02-0.04$ \\
& $\mathrm{Cu}$ & $\mathrm{N}$ & $\mathrm{S}$ & $\mathrm{Cr}$ & \\
Parent & $\sim 0.3$ & $\sim 0.0054$ & $\sim 0.007$ & $\sim 0.22$ & \\
LA-100 & $0.10-0.20$ & & $0.003-0.005$ & $0.02-0.05$ & \\
\hline
\end{tabular}

Table 1. Chemical compositions of the pearlitic rail steel and of the Superarc LA-100 welding wire. 

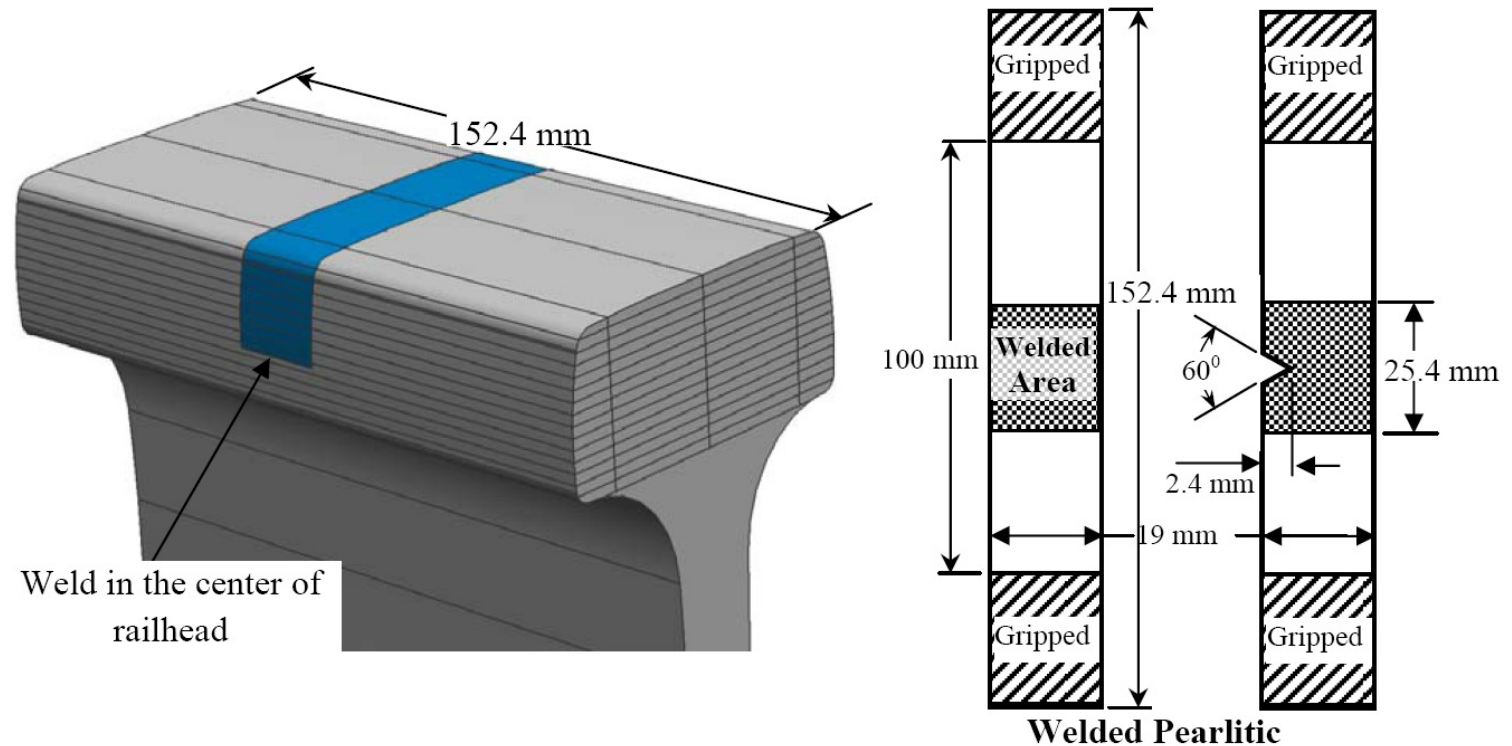

Figure 1. Schematic diagram of the railhead showing how specimens were machined (left) and the dimensions of the welded test specimens (right).

simulate the removal of materials from a railhead containing defects. A strip heater, $177.8 \mathrm{~mm}$ long and $38.1 \mathrm{~mm}$ wide, was placed on each side of the rail web in the center of the longitudinal direction. The strip heaters used had a maximum heat transfer of $250 \mathrm{~W}$ each. Finite element analysis (FEA) was performed to determine the temperature profile before and during welding and to determine the size of the HAZ. Before welding, the rail was preheated to $340^{\circ} \mathrm{C}$, to prevent cracking or inclusions in the weld. The groove was then filled using a Millermatic350, a gas metal arc welder. A heat input of $1397.6 \mathrm{KJ} / \mathrm{m}$ and a wire feed speed of $10.41 \mathrm{~m} / \mathrm{min}$ were employed. The welding wire used was the Superarc LA-100 manufactured by Lincoln Electric with chemical properties shown in Table 1. This wire was chosen because its mechanical properties were the closest match to that of the parent rail steel.

After welding, the excess weldment was removed from the rail steel by grinding. The rail was then cut into two halves with the weld in the center of both sections. Specimens were then machined from the welded pearlitic rail head along the direction of the rail using electrical discharge machining. A Unigraphics drawing of the welded rail after grinding is shown in Figure 1 along with the typical slices that were prepared for testing.

The welded pearlitic rail steel contains the weld in the center of the specimen and is $25.4 \mathrm{~mm}$ long. Both parent and welded rail steel had dimension of $152 \mathrm{~mm}$ length, $19 \mathrm{~mm}$ width, and $2 \mathrm{~mm}$ thickness. Notched specimens were also prepared with a $60^{\circ}$ notch at one free edge in the center of the specimen. The notch depth was approximately $2.4 \mathrm{~mm}$ with a notch depth to width ratio $(a / W)$ of 0.125 for both the pearlitic and welded rail steels. Static tensile tests were performed on both notched and unnotched specimens under displacement control mode using an MTS servohydraulic machine with TestStar data acquisition software. The results from the unnotched specimen were used to obtain the stress-strain relationship and the results from the notched specimen were used to obtain the residual strength and fracture properties. 


\section{Results and discussion}

3.1. Finite element analysis (FEA) of heated rail sections. FEA was used to study the heat transfer of the rail steel, with heat strips on opposite sides of the rail web, before and during the welding process. SolidWorks 2007 was utilized to perform the FEA. The temperature that was applied to the rail by the strip heaters in this study was $340^{\circ} \mathrm{C}$. This temperature was applied because the preheat temperature of high carbon steels should range from $260-425^{\circ} \mathrm{C}$, with the high carbon range being above $0.45 \%$ carbon [Lincoln 2005]. This implies that a thick material with carbon content of $1 \%$ should use a higher temperature from this range. The heat flux of the heaters was calculated as $Q / A$, where $Q$ is the amount of heat transferred and $A$ is the area of the heating surface. The heat flux of each electrical strip heater was calculated and found to be $36.93 \mathrm{KW} / \mathrm{m}^{2}$.

The boundary conditions that were used in the thermal analysis of the rail steel include: The web and base of the rail were considered adiabatic because fiber glass insulation was used to help prevent the loss of heat to the environment and the head of the rail was considered as undergoing convection since it was open to its surroundings. The ambient temperature used for this analysis was $26^{\circ} \mathrm{C}$ and the convection was calculated using the equation

$$
h=\frac{\mathrm{Nu} K}{L},
$$

where $h$ is the convective heat transfer coefficient, $\mathrm{Nu}$ is the Nusselt number, $K$ is the thermal conductivity, and $L$ is the average length of the railhead represented as a square. From this calculation, it was found that the convective heat transfer coefficient of the rail was $10.26 \mathrm{~W} / \mathrm{m}^{2} \mathrm{~K}$.

Prewelding. All the boundary conditions mentioned above were used in the prewelding analysis of the rail. The FEA heat distribution diagram was obtained for these conditions. From the plot it was noted that there is an insignificant variation in the temperature distribution in the rail, since the highest temperature was $340^{\circ} \mathrm{C}$ compared to the lowest, $310^{\circ} \mathrm{C}$. This is a difference of $30^{\circ} \mathrm{C}$. This demonstrates that the electrical strip heaters are very efficient in heating the groove to the desired temperature, even with the rail head exposed to the environment.

During welding. During welding, all the boundary conditions that were applied previously were applied again, along with one additional boundary condition. For this condition, it was assumed that the welding arc applied a heat of $4500^{\circ} \mathrm{C}$ and this heat was applied to a small circular location at the bottom of the groove. The assumption of $4500^{\circ} \mathrm{C}$ was based on an average value stated in the literature. The range given was between $3000^{\circ} \mathrm{C}$ to $6000^{\circ} \mathrm{C}$ for the temperature of the arc generated from a MIG welder [Dorzin 2003]. The plot of the heat distribution was obtained from the FEA. The distribution showed that the temperature at the arc was much higher than that of the heaters. It can be assumed from this observation that the temperature of the electrical strip heaters does not play a significant role in heating the groove during welding. However, the heat strips are still considered very important during welding because the process will be stopped at times to remove any inclusions that may be present in the weld, and the heaters will be needed to maintain the minimum interpass temperature during this period.

The temperature profile at the welding arc to the center of the rail web directly below the arc was studied to understand the temperature distribution of the arc on the rail; this distribution is shown in Figure 2a. The temperature is taken every $5 \mathrm{~mm}$ starting from the bottom of the groove. 

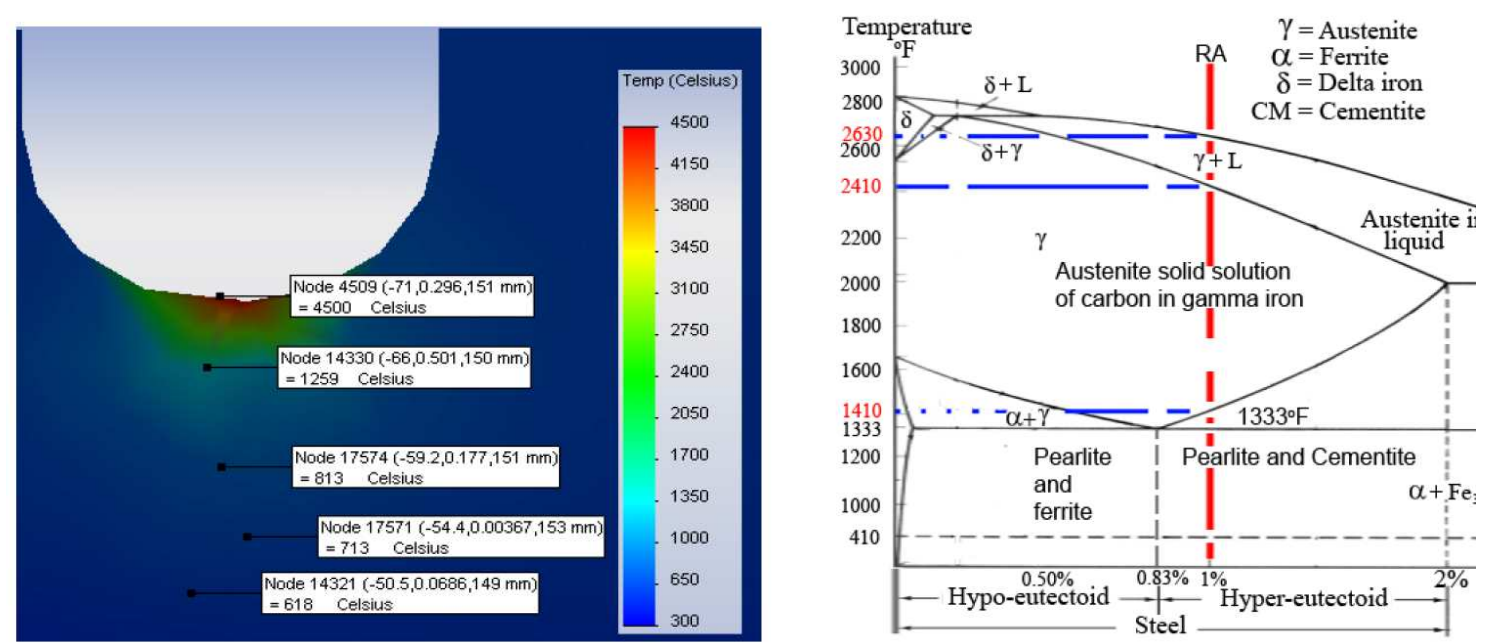

Figure 2. Left: Heat distribution during welding. Right: Iron-carbon phase diagram.

Studying this distribution in conjunction with the iron-carbon phase diagram shown in Figure $2 \mathrm{~b}$, taken from [Cornell and Bhadeshia 1999], will give a good indication of the sizes of the HAZ and the fusion zone. The line labeled RA shows the carbon content of the rail being studied. Following this line to the first change in the microstructure of the material would indicate the minimum temperature of the HAZ. The diagram shows that this temperature is $723^{\circ} \mathrm{C}$. Figure 2 a suggests that this temperature is reached approximately $15 \mathrm{~mm}$ from the center, so this length is indicative of the size of the HAZ. From the phase diagram it is seen that once the temperature reaches $1443^{\circ} \mathrm{C}$ all of the metal becomes liquid, which shows where the fusion would start. This region is at approximately $5 \mathrm{~mm}$, which shows that the rail should be properly fused with the weld metal.

3.2. Hardness distribution of welded pearlitic rail steel. The hardness distribution from the center of the weld was recorded using a handheld hardness tester. The first two slices of the rail were removed to expose the middle layers for hardness testing. The hardness distribution of the rail steel from the weld's center is shown in Figure 3, with the center of the weld being at $0 \mathrm{~mm}$ and the weld's width extending from $-12.7 \mathrm{~mm}$ to $12.7 \mathrm{~mm}$. The hardness of the rail is taken every $12.7 \mathrm{~mm}$.

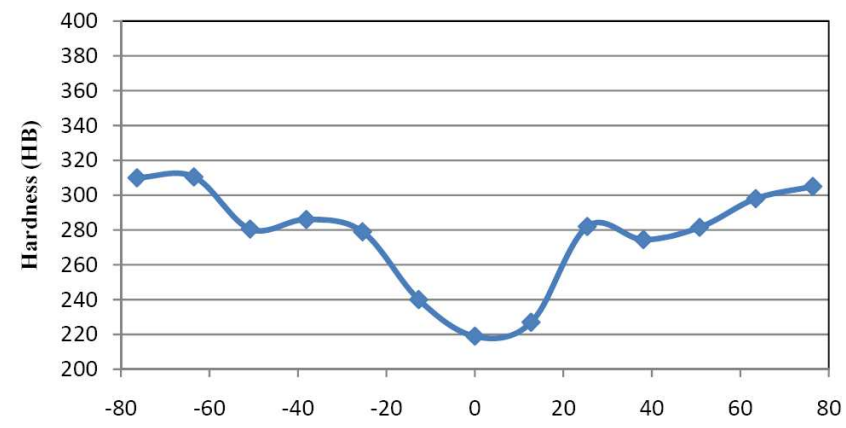

Figure 3. Hardness of rail steel versus distance to center of weld, in $\mathrm{mm}$. 
There is a clear trend to the right and to the left of the center of the weld, which shows that the further from the weld the harder the material. The two furthest points to the left and to the right of the weld, the parent rail, are in the range $300-315 \mathrm{HB}$. The graph shows that $20.4 \mathrm{~mm}$ to $50.8 \mathrm{~mm}$ to the right and left of the weld's center the hardness is slightly lower than the actual hardness of the rail, being in the range 279-286 HB. This decrease in hardness is associated with the HAZ, with decreased hardness due to the heat treatment produced during welding. The weld's hardness is significantly lower than the parent rail with a range of $220-240 \mathrm{HB}$. This hardness is due to the filler material used for welding and the heat treatment associated with multirun welds. The hardness of the weld and HAZ may be increased by heat treating the rail using a specific type of hardening technique, either induction or flame hardening. If this is not done the weld and HAZ will be prone to batter, leading to premature failure of the weld in service.

3.3. Microstructure of welded rail. The microstructure of the parent rail, HAZ, fusion line, and weld were studied using optical microscopy. The locations where the optical micrographs were taken are shown in Figure 4, together with sample micrographs at 100 times magnification. In the micrograph on the top left, taken in the parent rail, a typical pearlite microstructure is clearly seen. The pearlite microstructure consists of a fine lamellar aggregate of soft and ductile ferrite and very hard cementite. The micrograph on the top right shows that the microstructure of the HAZ has been altered by the welding process. This micrograph shows that the HAZ consists of a coarser pearlite structure than the parent rail.

The fusion zone of the weld shown in micrograph in Figure 4, bottom left, consists of the weld to the right and the HAZ to the left of the image. The change in the microstructure from the HAZ to the weld can be clearly seen and shows that the grain size of the weld is much smaller than that of the HAZ. The micrograph on the bottom right part of the figure reveals that the metallurgy of the weld is very different from that of the parent material. The weld material consists of a lower acicular ferrite plate structure containing small amounts of cementite. The dark regions between the ferrite consist of mainly martensite. This mixture containing mostly ferrite and small amounts of cementite and martensite explains the hardness of the weld; ferrite is soft while martensite and cementite are hard.

3.4. Stress-strain relationships. A comparative study was conducted on both the welded and parent pearlitic rail to study the effects of welding on the mechanical properties of the rail. The stress-strain relationships of the pearlitic rail steels used were previously studied [Aglan and Gan 2001; Aglan et al. 2004; 2006; 2007]. Figure 5, left, shows the average stress-strain curves for the welded and parent pearlitic rail steel. Both curves consist of linear elastic behavior followed by nonlinear plastic behavior until failure. However, the elastic modulus of the welded pearlitic rail steel is higher than that of the parent pearlitic rail steel, with that for the welded rail being $275 \mathrm{GPa}$ and for the parent rail being $200 \mathrm{GPa}$ [Aglan and Gan 2001]. The figure also shows that the nonlinear plastic portion of the welded rail's curve falls below that of the parent rail. This shows that the welded rail's tensile strength is not as high as the parent rail. The strain to failure of the welded rail shows a significant decrease which reveals that the welded rail is not as ductile as the parent rail.

Table 2 lists the mechanical properties for both the welded and parent pearlitic rail steels. The ultimate strength declined by $47 \%$ from $1114 \mathrm{MPa}$ for the parent rail to $760 \mathrm{MPa}$ for the welded rail. The weld efficiency is the ratio of the weld-to-parent ultimate tensile strength, found to be $68 \%$. The yield strength had a negligible decline of 5\% from $624 \mathrm{MPa}$ for the parent rail to $595 \mathrm{MPa}$ for the welded rail. This negligible decline is very positive as the yield strength is used in design rather than the ultimate tensile 


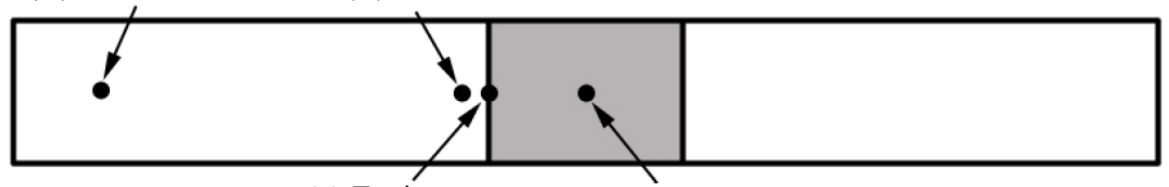

(c) Fusion

(d) Weld

(a) Parent rail

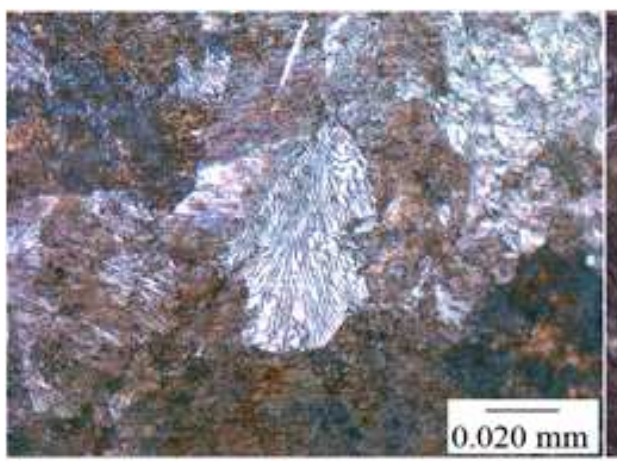

(b) HAZ

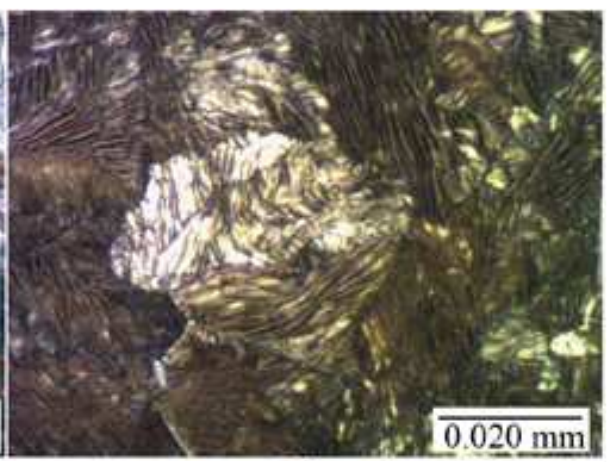

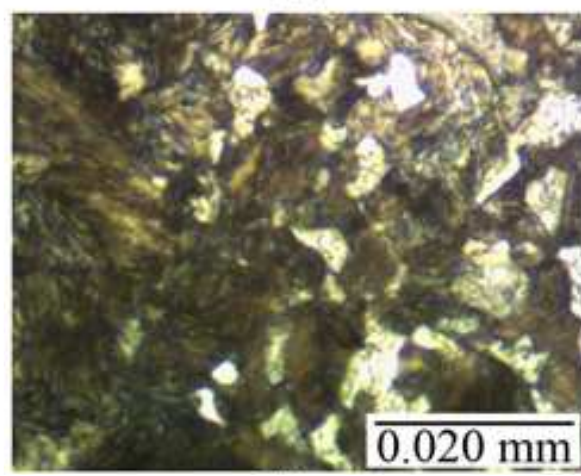

(c) Fusion

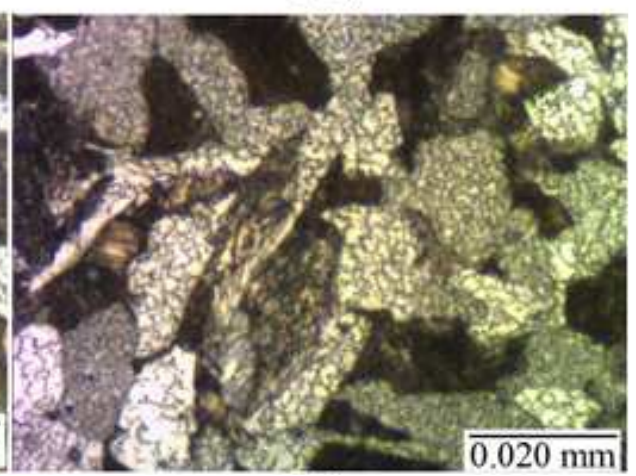

(d) Weld

Figure 4. Micrographs at 100 times of the rail steel examined. The sections correspond to the points marked on the diagram.
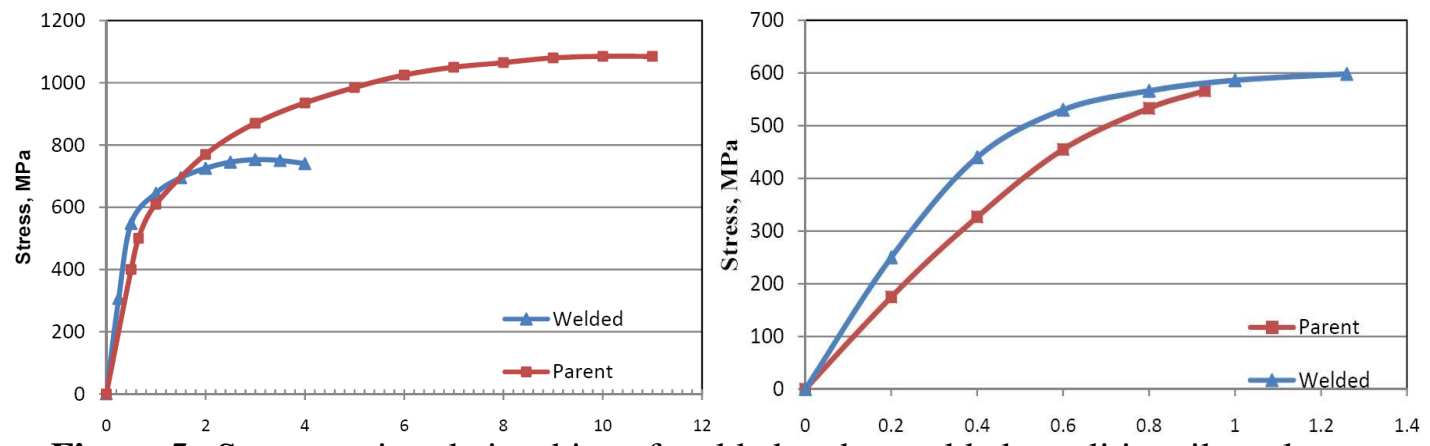

Figure 5. Stress-strain relationships of welded and unwelded pearlitic rail steels: unnotched (left) and notched (right). The horizontal axis shows the percent strain. 


\begin{tabular}{|ccccc|}
\hline Condition & Specimen number & Ultimate strength & Yield strength & Failure strain $(\%)$ \\
\hline \multirow{2}{*}{ Welded } & 1 & 865 & 650 & 3.34 \\
& 2 & 695 & 580 & 3.98 \\
& 3 & 726 & 585 & 3.81 \\
& 4 & 755 & 565 & 4.46 \\
& Average & 760 & 595 & 3.90 \\
\hline \multirow{2}{*}{ Parent } & 1 & 1161 & 667 & 11.3 \\
& 2 & 1059 & 548 & 11.8 \\
& 3 & 1121 & 657 & 10.2 \\
& Average & 1114 & 624 & 11.1 \\
\hline
\end{tabular}

Table 2. Ultimate and yield strengths (in MPa) and failure strain of welded and parent pearlitic rail steel specimens.

strength. The strain to failure decreased from $11.1 \%$ for the parent rail to $3.9 \%$ for the welded rail, a two-fold decrease in ductility.

The parent and welded rail steel materials with simulated defects were tested to determine their residual strengths. A notch was created using a triangular file with a crack length to sample width ratio of 0.125 . The specimens were tested and the unnotched cross sectional area was used to calculate the stress. The average stress-strain relationship for both the parent and welded rail steel is shown in Figure 5, right. This figure shows that the average residual strength of the welded rail is slightly higher than that of the parent rail. The strain to failure of the welded rail is also higher than that of the parent rail. The parent rail has a linear elastic behavior followed by a very short nonlinear plastic behavior until failure, while the welded rail has a linear elastic behavior followed by a longer nonlinear plastic behavior until failure.

The mechanical properties of the notched parent and welded pearlitic rail steel specimens are shown in Table 3. This table shows an increase of 5\% in the residual strength from $566 \mathrm{MPa}$ for the parent rail

\begin{tabular}{|cccccc|}
\hline Condition & Specimen number & $\mathrm{K}_{1}$ & Residual strength & Failure strain (\%) & Notch sensitivity \\
Welded & 1 & 53 & 588 & 1.22 & 0.23 \\
& 2 & 50 & 577 & 0.78 & 0.24 \\
& 3 & 59 & 631 & 1.77 & 0.17 \\
\multirow{5}{*}{ Parent } & Average & 54 & 598 & 1.26 & 0.21 \\
& 1 & 84 & 685 & 1.1 & 0.39 \\
& 2 & 56 & 457 & 0.7 & 0.59 \\
& 3 & 84 & 683 & 1.1 & 0.39 \\
& 4 & 54 & 438 & 0.8 & 0.61 \\
& Average & 70 & 566 & 0.93 & 0.49 \\
\hline
\end{tabular}

Table 3. Mechanical properties of notched welded and parent pearlitic rail steel specimens $\left(\mathrm{K}_{1}\right.$ in units of MPa $\mathrm{m}^{0.5}$ and residual strength in units of MPa). 
to $598 \mathrm{MPa}$ for the welded rail. There is a considerable increase of $26 \%$ in the ductility of the welded rail over the parent rail, with the strains to failure being $1.26 \%$ and $0.93 \%$ respectively. The notch sensitivity is defined as $\left(S_{u t}-S_{r}\right) / S_{u t}$ where $S_{r}$ is the residual strength and $S_{u t}$ is the ultimate tensile strength of the unnotched specimen. The notch sensitivity decreased from 0.49 for the parent rail to 0.21 for the welded rail. This shows that the parent rail is a lot more sensitive to the introduction of a notch than the welded rail.

The notched parent rail steel has an average residual strength of $566 \mathrm{MPa}$ which is a $51 \%$ decrease in the ultimate tensile strength of the unnotched specimen. The average residual strength of the welded rail steel is $598 \mathrm{MPa}$ which is a $27 \%$ decrease in the ultimate tensile strength of the unnotched welded rail steel. The average strain to failure, which is a measure of the ductility of the material, decreased from $11.1 \%$ for the unnotched parent specimens to $0.93 \%$ for the notched parent specimen which is almost a 12 fold decrease in ductility. This is compared to the average strain to failure of the notched welded rail steel, which was $1.26 \%$, a mere 3 fold decrease from $3.9 \%$ for the unnotched welded rail steel. As a result of the introduction of a notch equal to 0.125 of the specimen width, the parent material lost almost half of its strength compared to the welded material, which only lost approximately a quarter of its strength. The introduction of the notch also caused the parent material to lose practically all its ductility, showing high notch sensitivity. The welded material, however, only lost a small fraction of its ductility when compared to the parent material, showing low notch sensitivity.

The test results show that the samples failed in the center of the weld. This happened in all tests. This failure reveals that the fusion between the parent rail and the weld material was very good and that there was perfect fusion, else failure would have occurred at the fusion line. The failure in the center of welded area also confirms that the weld is not as strong as the parent rail. The welded specimen also shows a significant amount of necking which demonstrates that the weld material is ductile. This shows that even if there is a defect or crack in the rail steel during service there might not be a catastrophic failure due to the high ductility of the weld.

3.5. Plain stress fracture toughness evaluation. Equations (1) and (2) were used to calculate the fracture toughnesses of the parent and welded rail steel. To qualify as a plain strain fracture toughness, as stated before, the thickness, $t$, and crack length, $a$, must both be greater than $2.5 \times\left(K_{1 c} / \sigma_{y s}\right)^{2}$. Using $\sigma_{y s}=595 \mathrm{MPa}$ and $K_{1 c}=54 \mathrm{MPa} \sqrt{m}$, gives $2.5 \times(54 / 595)^{2}=20.6 \mathrm{~mm}$. This value is much larger than both the thickness and the crack length. Therefore, this is not considered a valid $K_{I C}$ and is referred to as the plain stress fracture toughness $K_{1}$.

The plain stress fracture toughness of the parent material is $70 \mathrm{MPa} \sqrt{m}$ compared to $54 \mathrm{MPa} \sqrt{m}$ for the welded material. This is a $30 \%$ decrease in the fracture toughness for the parent compared with that for the welded rail material. However, the residual strength, strain to failure, and notch sensitivity of the welded rail are all better than those of the parent rail.

3.6. Fractography. A schematic representation of the fracture surface is shown in Figure 6, top. The notch is on the left side of the figure, which means the crack propagation direction is from left to right. Points A and B represent the locations at which SEM micrographs were taken. Immediately ahead of the crack tip, at point $\mathrm{A}$, is referred to as the crack initiation region, while close to the end of the fracture surface, at point $\mathrm{B}$, and is referred to as the fast crack propagation region. The fracture surface morphology of the parent and welded rail steel, respectively are shown in the top and bottom micrographs 

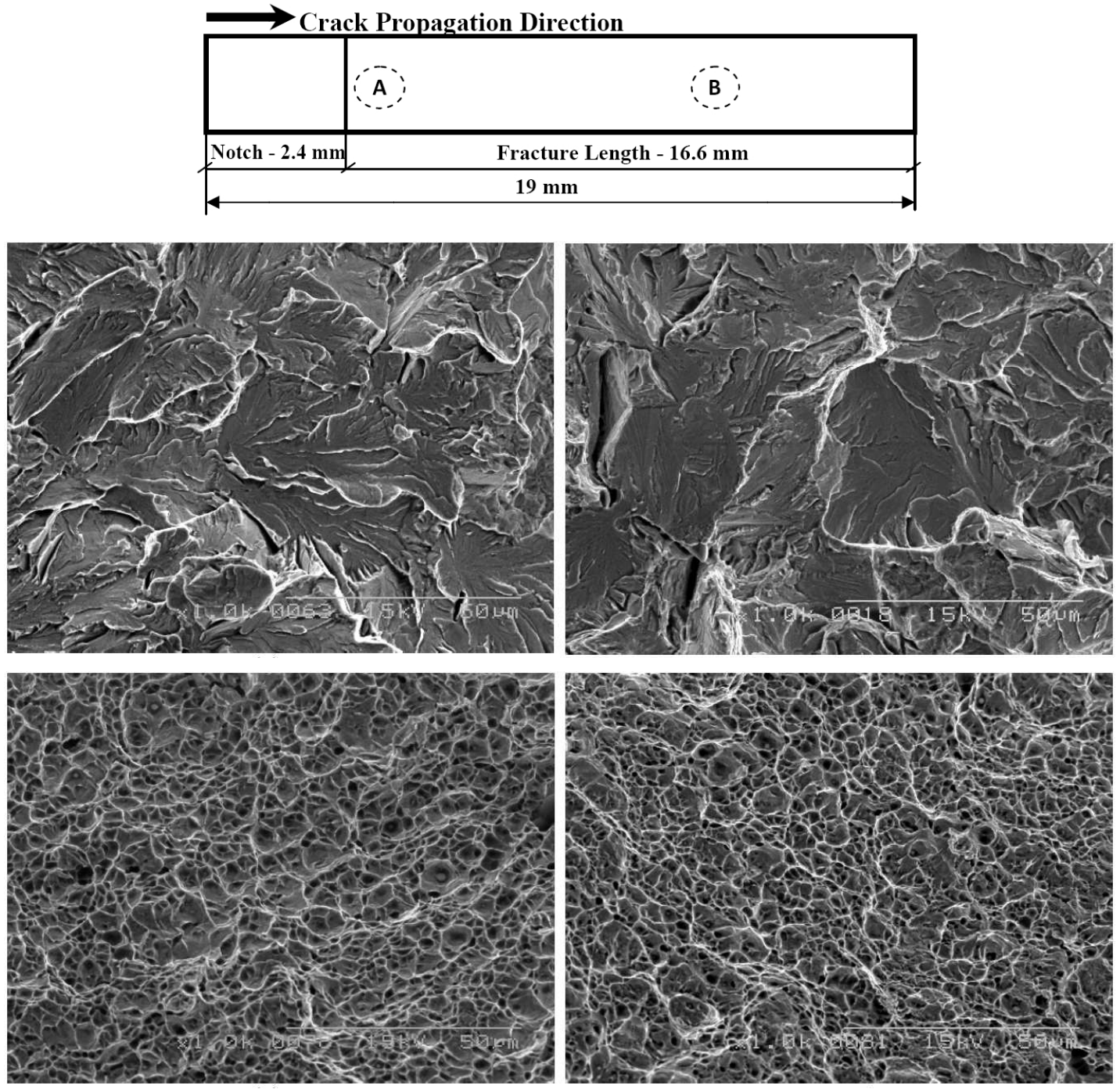

Figure 6. SEM micrograph at 1000 times of the parent rail (top row) and welded rail (bottom row) at the beginning of the notch (left column, region $\mathrm{A}$ in the diagram) and toward the end of the fracture surface (right column, region B in the diagram).

in Figure 6: the micrographs on the left were taken at point A, and those on the right at point B. All these micrographs were taken at 1000 times magnification.

The fracture surface morphology of the parent pearlitic rail steel specimen taken immediately ahead of the crack tip can be seen in the top left micrograph. The image displays cleavage facets and river patterns. The entire fracture surface contains well-drawn ferrite strips. Pulled up lamellae and tearing ridgelines inside the grains can also be seen [Khourshid et al. 2001]. The fracture surface of the parent rail taken from location $B$ is shown in the top right micrograph. The fracture surface displays a mixed type of fracture mechanism with the ductile mechanism dominant. The ductile behavior is evident in the micrograph from ductile tearing features such as pulled up ferrite strips and tearing ridges. Small 
amounts of cleavage facets and river patterns can also be seen, which are associated with brittle fracture. In some areas, there exist intergranular cracks along the grain boundaries as shown in the left hand section of the micrograph. It is observed that further from the fracture surface the failure mechanism becomes less ductile.

The fracture surface morphology of the welded rail steel taken from location A consists of a dimpled appearance and can be seen in the bottom left micrograph in Figure 6. Dimpled rupture is created by microvoid coalescence, which is formed as a result of particle matrix decohesion or cracking of secondphase particles [Davis 1998, pp. 1212-1216]. This type of fracture morphology is associated with ductile fracture. The fracture morphology of the welded rail steel taken at location B is shown in the bottom right micrograph, which looks very similar to the one taken at location A. This similarity shows that the entire fracture surface of the welded rail steel consists of a dimpled appearance, and also explains its relatively high ductility.

\section{Concluding remarks}

- Finite element analysis revealed that the sizes of the heat affected zone (HAZ) and fusion zone of the pearlitic rail steel under consideration are approximately $15 \mathrm{~mm}$ and $5 \mathrm{~mm}$ respectively at a preheat temperature of $340^{\circ} \mathrm{C}$ and an arc temperature of $4500^{\circ} \mathrm{C}$.

- The pearlitic rail, welded rail, and HAZ had hardness ranges of 300-315 HB, 200-240 HB, and 279-286 HB respectively.

- The parent rail steel has ultimate tensile strength, yield strength, and elongation of about $1114 \mathrm{MPa}$, $624 \mathrm{MPa}$, and $11.1 \%$ respectively while the welded rail steel has $760 \mathrm{MPa}, 595 \mathrm{MPa}$, and $3.90 \%$ respectively.

- The average residual strength of the welded rail was slightly higher than that of the parent rail and the parent rail was more sensitive to the introduction of a notch.

- The average plain stress fracture toughnesses of the parent and welded rail steels were $70 \mathrm{MPa} \cdot \mathrm{m}^{0.5}$ and $54 \mathrm{MPa} \cdot \mathrm{m}^{0.5}$ respectively.

- The fracture surface morphologies of both the parent and welded rail steel display ductile failure mechanisms. However, the failure mechanisms seen in the welded rail steel are more ductile than those in the pearlitic rail steel.

\section{References}

[Aglan and Fateh 2006] H. Aglan and M. Fateh, "Fatigue damage tolerance of bainitic and pearlitic rail steels", Int. J. Damage Mech. 15:4 (2006), 393-410.

[Aglan and Fateh 2007] H. Aglan and M. Fateh, "Fracture and fatigue crack growth analysis of rail steels", J. Mech. Mater. Struct. 2:2 (2007), 335-346.

[Aglan and Gan 2001] H. Aglan and Y. X. Gan, "Fatigue crack growth analysis of a premium rail steel", J. Mater. Sci. 36:2 (2001), 389-397.

[Aglan et al. 2004] H. Aglan, Z. Y. Liu, M. F. Hassan, and M. Fateh, "Mechanical and fracture behavior of bainitic rail steel", J. Mater. Process. Technol. 151:1-3 (2004), 268-274.

[Bhadeshia 1997] H. K. D. H. Bhadeshia, "Models for the elementary mechanical properties of steel welds", pp. 229-284 in Mathematical modelling of weld phenomena 3 (Graz, 2005), edited by H. Cerjak, Institute of Materials, London, 1997. 
[Chandler 2008] J. Chandler, Field welding inspection guide, Ohio Department of Transportation, Department of Materials Management, Columbus, OH, 2008, Available at http://tinyurl.com/ODOT-OMM-FWIG.

[Cornell and Bhadeshia 1999] R. Cornell and H. K. D. H. Bhadeshia, "Decarburization of steel", online material, University of Cambridge, Department of Materials Science and Metallurgy, 1999, Available at http://www.msm.cam.ac.uk/phasetrans/ abstracts/M0.html.

[Crear 2001] R. Crear, Engineering design: inspection, evaluation, and repair of hydraulic steel structures, US Army Corps of Engineers, Washington, DC, 2001, Available at http://tinyurl.com/USACE-EM-1110-2-6054. Publication EM 1110-2-6054.

[Davis 1998] J. R. Davis (editor), Metals handbook, Desk ed., 2nd ed., ASM International, Materials Park, OH, 1998.

[Dorzin 2003] E. Dorzin, “Temperature of a MIG welder”, 2003, Available at http://tinyurl.com/temp-MIG-welder.

[El-Banna et al. 2000] E. M. El-Banna, M. S. Nageda, and M. M. Abo El-Saadat, "Study of restoration by welding of pearlitic ductile cast iron", Mater. Lett. 42:5 (2000), 311-320.

[Funderburk 1997] R. S. Funderburk, "Fundamentals of preheat”, Weld. Innov. 14:2 (1997), 14-15.

[Funderburk 1999] R. S. Funderburk, "How hot is hot enough? A primer on weldment preheating and interpass temperature", Weld. Des. Fabr. 72:5 (1999), 40-44.

[Funderburk 2000] R. S. Funderburk, “Taking your weld's temperature”, Mod. Steel Constr. 40:2 (2000), 56-61.

[Gray et al. 1982] G. T. Gray, III, A. W. Thompson, J. C. Williams, and D. H. Stone, "The effect of microstructure on fatigue crack propagation in pearlitic eutectoid steels", Can. Metall. Q. 21 (1982), 73-78.

[Khourshid et al. 2001] A. M. Khourshid, Y. X. Gan, and H. A. Aglan, "Microstructure origin of strength and toughness of a premium rail steel", J. Mater. Eng. Perform. 10:3 (2001), 331-336.

[Kim et al. 2001] J. H. Kim, Y. J. Oh, I. S. Hwang, D. J. Kim, and J. T. Kim, "Fracture behavior of heat-affected zone in low alloy steels", J. Nucl. Mater. 299:2 (2001), 132-139.

[Lewandowski and Thompson 1986] J. J. Lewandowski and A. W. Thompson, "Microstructural effects on the cleavage fracture stress of fully pearlitic eutectoid steel”, Metall. Mater. Trans. A 17:10 (1986), 1769-1786.

[Lincoln 2005] Hardfacing guide: product and procedure selection, Lincoln Electric Company, Cleveland, OH, 2005, Available at http://tinyurl.com/LE-C7-710. Publication C7.710.

[Little and Kamtekar 1998] G. H. Little and A. G. Kamtekar, "The effect of thermal properties and weld efficiency on transient temperatures during welding”, Comput. Struct. 68:1-3 (1998), 157-165.

[Mutton and Alvarez 2004] P. J. Mutton and E. F. Alvarez, "Failure modes in aluminothermic rail welds under high axle load conditions", Eng. Fail. Anal. 11:2 (2004), 151-166.

[Orange 1966] T. W. Orange, "Evaluation of special 301-type stainless steel for improved low-temperature notch toughness of cryoformed pressure vessels", Technical Note D-3445, NASA/Lewis Research Center, Washington, DC/Cleveland, OH, 1966, Available at http://tinyurl.com/NASA-TN-D-3445.

[Reis and Harness 2004] T. L. Reis and D. J. Harness, "Field welding inspection manual", Materials Instructional Memo 558 (version of April 20, 2004), 2004, Available at http://tinyurl.com/IDOT-MIM-558-2004.

[Saarna and Laansoo 2004] M. Saarna and A. Laansoo, "Rail and rail weld testing", pp. 217-219 in Proceedings of the 4th International Conference of DAAAM: Industrial Engineering - Innovation as Competitive Edge For SME (Tallinn, 2004), edited by J. Papstel and B. Katalinic, DAAAM Estonia, Tallinn University of Technology, Tallinn, 2004.

[Sugden and Bhadeshia 1989] A. A. B. Sugden and H. K. D. H. Bhadeshia, "Lower acicular ferrite", Metall. Mater. Trans. A 20:9 (1989), 1811-1818.

[Tojo 2003] M. Tojo, "Welding of offshore structures, 2: Essential factors in welding procedure controls", Kobelco Weld. Today 6:2 (2003), 3-7.

[WTIA 2006] Repair welding of crane rails using arc welding processes, Welding Technology Institute of Australia, Newington, NSW, 13 May 2006, Available at http://tinyurl.com/WTIA-TGN-BC-05. Technical Guidance Note TGN-BC-05.

Received 22 Jan 2009. Revised 2 Jul 2009. Accepted 7 Jul 2009. 
Aldinton AlliE: aallie7239@mytu.tuskegee.edu

Mechanical Engineering Department, Tuskegee University, Tuskegee, AL 36088, United States

Heshmat A. Aglan: aglanh@tuskegee.edu

College of Engineering, Architecture and Physical Sciences, 218 Foster Hall, Tuskegee University, Tuskegee, AL 36088, United States

MAHMOOD FATEH: mahmood.fateh@dot.gov

Federal Railroad Administration, 1120 Vermont Avenue NW, Mail Stop 20, Washington, DC 20590, United States 


\title{
JOURNAL OF MECHANICS OF MATERIALS AND STRUCTURES
}

\author{
http://www.jomms.org
}

\author{
Founded by Charles R. Steele and Marie-Louise Steele

\section{EDITORS} \\ Charles R. STEele \\ DAVIDE BIGONI \\ IWONA JASIUK \\ YASUHIDE SHINDO \\ Stanford University, U.S.A. \\ University of Trento, Italy \\ University of Illinois at Urbana-Champaign, U.S.A. \\ Tohoku University, Japan
}

\section{EDITORIAL BOARD}

H. D. BUI École Polytechnique, France

J. P. CARTER University of Sydney, Australia

R. M. Christensen Stanford University, U.S.A.

G. M. L. GLADWELL University of Waterloo, Canada

D. H. HodGES Georgia Institute of Technology, U.S.A.

J. HUTCHINSON Harvard University, U.S.A.

C. HwU National Cheng Kung University, R.O. China

B. L. KariHaloo University of Wales, U.K.

Y. Y. KIM Seoul National University, Republic of Korea

Z. Mroz Academy of Science, Poland

D. PAMPlonA Universidade Católica do Rio de Janeiro, Brazil

M. B. RUBIN Technion, Haifa, Israel

A. N. SHUPIKov Ukrainian Academy of Sciences, Ukraine

T. TARNAI University Budapest, Hungary

F. Y. M. WAN University of California, Irvine, U.S.A.

P. WRIGGERS Universität Hannover, Germany

W. YANG Tsinghua University, P.R. China

F. ZIEGLER Technische Universität Wien, Austria

\section{PRODUCTION}

\section{Paulo Ney de Souza Production Manager \\ SheIla Newbery Senior Production Editor \\ SILVIO LEVY Scientific Editor}

See inside back cover or http://www.jomms.org for submission guidelines.

JoMMS (ISSN 1559-3959) is published in 10 issues a year. The subscription price for 2010 is US $\$ 500 /$ year for the electronic version, and \$660/year (+\$60 shipping outside the US) for print and electronic. Subscriptions, requests for back issues, and changes of address should be sent to Mathematical Sciences Publishers, Department of Mathematics, University of California, Berkeley, CA 94720-3840.

JoMMS peer-review and production is managed by EditFLOW ${ }^{\mathrm{TM}}$ from Mathematical Sciences Publishers.

PUBLISHED BY

mathematical sciences publishers

http://www.mathscipub.org

A NON-PROFIT CORPORATION

Typeset in LATEX

CCopyright 2010. Journal of Mechanics of Materials and Structures. All rights reserved. 


\title{
Journal of Mechanics of Materials and Structures
}

\author{
Volume 5, No. 2 February 2010
}

A critical analysis of interface constitutive models for the simulation of delamination in composites and failure of adhesive bonds

Anton Matzenmiller, Sebastian Gerlach and Mark Fiolka

185

Computational studies of collagen fibril biominerals using a virtual internal bond

model with extrinsic length scale

Ganesh Thiagarajan and Kavita Deshmukh

The simulation of stochastically excited viscoelastic systems and their stability

VADIM D. POTAPOV

Fundamental solutions for an inhomogeneous cross-anisotropic material due to horizontal and vertical plane strain line loads

Cheng-Der Wang, Jia-YAN Hou and WeI-Jer WANG

Mechanical and fracture analysis of welded pearlitic rail steels

Aldinton Allie, Heshmat A. Aglan and Mahmood Fateh

Rate dependence of indentation size effects in filled silicone rubber

Ramanjaneyulu V. S. TATIRAJU and ChUng-SOUK HAN

A novel application of a laser Doppler vibrometer in a hèalth monitoring system

DAVOOD REZAEI and FARID TAHERI

Energy absorption of a helicoidal bistable structure

Seubpong Leelavanichkul, Andrej Cherkaev, Daniel O. Adams

and FLORIAN SOLZBACHER

Decay properties of solutions of a Mindlin-type plate model for rhombic systems

Francesca Passarella, Vincenzo Tibullo and VitTorio Zampoli

A consistent refinement of first-order shear deformation theory for laminated composite and sandwich plates using improved zigzag kinematics Alexander Tessler, Marco Di Sciuva and Marco Gherlone 